\title{
Afectación y desafectación de bienes familiares: Hacia una conciliación entre normas de derecho constitucional y derecho de familia
}

\author{
Affectation and disaffection of family assets: Towards a reconciliation between \\ constitutional law and family law rules
}

\author{
José Luis López Blanco \\ Abogado, Chile
}

\begin{abstract}
RESUMEN La institución de los bienes familiares, incorporada al Código Civil por la Ley 19.335 de 1994, tuvo como objetivo principal proteger, a solicitud de parte y ante eventualidades de cualquier tipo, tanto el inmueble de residencia principal de la familia (entendida como la surgida de un matrimonio civil) como los bienes muebles que guarnece, generando una serie de limitaciones sobre la posibilidad de disponer de los bienes afectos a esta calidad. Por lo anterior, se hace necesario efectuar un análisis que permita conciliar por medio de la revisión de antecedentes legislativos, doctrinarios y jurisprudenciales, el alcance de esta institución del derecho de familia con el reconocimiento del derecho de propiedad que realiza el artículo 19 numeral 24. ${ }^{\circ}$ de la Constitución Política de la República.
\end{abstract}

PALABRAS CLAVE Bienes familiares, derecho de propiedad, libertad económica, derecho de familia, primacía constitucional.

ABSTRACT The institution of family assets, incorporated into the Civil Code by Law 19.335 of 1994, had as its main objective to protect, both at the request of a party and in the event of any type, both the main residence property of the family (understood as such arising of a civil marriage) as the movable property that garnish, generating a series of limitations on the possibility of disposing of the goods affected to this quality. Therefore, it is necessary to carry out an analysis that allows to reconcile, by means of the review of legislative, doctrinal and jurisprudential antecedents, the scope of this institution of family law with the recognition of the property right that article 19 No. 24 of the Political Constitution of the Republic.

KEYWORDS Family assets, property rights, economic freedom, family law, constitutional primacy. 


\section{Institución de bienes familiares}

La institución de los «bienes familiares», que se estableció por la Ley 19.335 de 1994, se encuentra reglamentada en los artículos 141 y siguientes del Código Civil. El primero de estos artículos dispone que:

El inmueble de propiedad de cualquiera de los cónyuges que sirva de residencia principal de la familia, y los muebles que la guarnecen, podrán ser declarados bienes familiares y se regirán por las normas de este párrafo, cualquiera sea el régimen de bienes del matrimonio [el énfasis es nuestro].

Una sentencia de la Corte de Santiago (rol 6754-2017, 2018, considerando tercero) los ha definido como:

Bienes corporales o incorporales, de propiedad de uno o de ambos cónyuges que, en ciertas circunstancias, pueden ser considerados esenciales para la adecuada subsistencia de la familia, restringiéndose los derechos que sobre ellos correspondan a su titular, sea por una resolución judicial, sea por un acto unilateral de uno de los cónyuges [el énfasis es nuestro].

La norma citada permite que, en ciertas circunstancias, puedan ser declarados bienes familiares el inmueble de propiedad de cualquiera de los cónyuges que sirva de residencia principal de la familia y los muebles que la guarnecen. Para estos efectos, el juez, al recibir esta petición, citará a una audiencia preparatoria en la que deben presentarse los antecedentes que la justifiquen. Si el juez considerase que faltan antecedentes, "citará a la audiencia de juicio».

Agrega el artículo 141, en su inciso tercero, lo siguiente: "Con todo, la sola interposición de la demanda transformará provisoriamente en familiar el bien de que se trate». De esto, se puede concluir que para el legislador es tan importante el concepto de "protección de la familia» que ante la sola presentación de la demanda, sin mayores antecedentes ni un estudio detallado de la situación de aquel grupo familiar, la ley ordena afectar de inmediato la calidad de «familiar» al inmueble objeto de aquella petición. Si en aquella audiencia preparatoria el juez considera que faltan antecedentes para resolver, como expresa la disposición legal citada, se citará a la audiencia de juicio.

Esto significa que, en una primera instancia, considerando el valor que nuestro sistema jurídico otorga a la familia, la ley permite limitar muy severamente las garantías que protegen el dominio que sobre aquel inmueble tiene el cónyuge propietario, sin perjuicio de lo que corresponda resolver por el tribunal en la audiencia pertinente, con toda la información del caso, en que se deberá acreditar por el cónyuge que lo solicita la existencia de las circunstancias que lo ameritan.

Se puede concluir entonces que, en la audiencia de juicio, donde se resolverá derechamente la petición, la parte que solicite la afectación deberá acompañar todos los antecedentes que la justifiquen, los que de acuerdo con la normativa aplicable a estos tribunales, el juez deberá estudiar cuidadosamente. 
Incluso más, el artículo 141 hace presente la responsabilidad que tiene el cónyuge que solicita esta medida, el que en caso de actuación fraudulenta para obtener la declaración podría estar sujeto a sanciones civiles y de carácter penal.

Por lo mismo, la primera afectación que se otorga sin otra causa que la sola presentación de la demanda, está sujeta a una posible revocación en cuanto el tribunal, al efectuar un cuidadoso examen de todos los antecedentes, podría concluir que existen otras formas y circunstancias de proteger el interés de la familia y de determinar su residencia. Para ello, el tribunal deberá necesariamente, según se expresa más adelante, considerar diversos antecedentes propios de la legislación de familia.

La disposición legal citada permite concluir que este derecho, que se puede conceder a uno de los cónyuges que lo solicite, no es absoluto, requiriéndose la presentación de antecedentes que justifiquen aquella petición y que sean aceptados por el tribunal.

Para llegar a esta conclusión se deben considerar los siguientes criterios:

- En primer lugar, la disposición legal del artículo 141 del Código Civil contiene la fórmula verbal «podrán» con respecto a la declaración de bien familiar de dicho inmueble y de los muebles que allí se guarnecen. Esto significa que existe la facultad o potencia de hacer algo, o la facultad o jurisdicción que alguien tiene para mandar o ejecutar algo según la definición del Diccionario de la Real Academia Española. Esto es, que el tribunal de familia tiene la opción de escoger y de determinar si, en definitiva, acoge la petición o no.

- En segundo lugar, la propia ley dispone que se requieren «antecedentes» que justifiquen dicha decisión. En ese artículo no se definen cuáles son estos antecedentes. Sin embargo, la norma señala que estos bienes se regirán por las normas de ese párrafo. Según se comenta más adelante en este mismo trabajo, el artículo 147 del Código Civil, que se encuentra precisamente en ese párrafo, contiene algunos criterios que permiten una clarificación al respecto.

- En tercer lugar, se advierte al cónyuge que actúe «fraudulentamente» para obtener esta declaración que estará sujeto a sanciones civiles y penales. El concepto de «actuación fraudulenta» da a entender que «los antecedentes» que dicho cónyuge presentó al tribunal pueden haber sido obtenidos con engaño, para convencer al tribunal de la legitimidad y justificación de su solicitud.

En suma, la declaración de bien familiar del inmueble de propiedad de cualquiera de los cónyuges y los muebles que la guarnecen no requiere solo que el inmueble sirva de residencia principal de la familia, sino que es necesario adjuntar antecedentes que la justifiquen y que cumplan con los requisitos establecidos en el párrafo, principalmente aquellos que se deducen de lo dispuesto en el artículo 147 del Código Civil, así como de otras disposiciones del derecho de familia coincidentes con esos criterios. 


\section{Antecedentes requeridos para la afectación de un bien}

Como se menciona en el párrafo anterior, la ley no es explícita para precisar cuáles son los «antecedentes» que justifican la afectación de un bien como familiar. Tampoco la norma legal determina en qué consistiría la «actuación fraudulenta» del cónyuge no propietario para obtener, indebidamente, dicha afectación.

En consecuencia, para efectuar un análisis más profundo de los conceptos recién mencionados se hace necesario considerar otras disposiciones legales relativas a la misma materia, principalmente aquellas que regulan las relaciones patrimoniales de familia.

A este respecto, el artículo 142 del Código Civil señala que para enajenar o gravar los bienes familiares se requiere la autorización del cónyuge no propietario, la que deberá ser específica y otorgada por escrito.

El artículo 144 del Código Civil dispone que si hubiese «necesidad» de disponer del bien afectado, la voluntad del cónyuge no propietario, en caso de negativa, «que no se funde en el interés de la familia», podrá ser suplida por el juez.

Llama la atención esta norma que se pone en el caso de que exista «necesidad de disponer» del bien familiar. Cabe preguntarse, ¿por qué habría necesidad de disponer de este bien? La ley no lo explica. Solo cabe imaginarse que, como ocurre en muchas familias chilenas, surjan a futuro necesidades económicas apremiantes en que sea «necesaria» la venta de este bien. La ley habla de «necesidad» y no de conveniencia, oportunidad, ventaja u otro término semejante. Los casos de «necesidad», que sin duda será de naturaleza económica y muy severa, pueden ser muy variados y diversos. A título de mero ejemplo, se puede pensar en el pago de deudas o un requerimiento especial por motivos de salud, o la necesidad de capital para un emprendimiento. Lo importante es que la ley advierte esta posible situación futura y dispone que, en caso de negativa del cónyuge no propietario para la venta del bien afectado, su voluntad podrá ser suplida por el juez cuando aquella negativa «no se funde en el interés de la familia».

La disposición legal citada es importante por cuanto confirma que este derecho a calificar un bien como familiar no es absoluto, por lo que puede ser revocado. Adicionalmente, el texto legal agrega que para resolver sobre esta materia, tanto en el momento de la declaración de bien familiar como para autorizar su disposición posterior, el juez debe considerar «el interés de la familia».

En otra perspectiva, bien puede ocurrir que las circunstancias que existían al tiempo de la afectación de ese inmueble hayan variado sustancialmente o hasta puedan no existir.

Por otro lado, el artículo 147 del Código Civil, que faculta al juez para constituir prudencialmente a favor del cónyuge no propietario derechos de usufructo, uso o habitación sobre los bienes familiares, dispone que:

En la constitución de esos derechos y en la fijación del plazo que les pone término, el juez tomará especialmente en cuenta el interés de los hijos, cuando los haya, y las fuerzas patrimoniales de los cónyuges. 
Por su lado, el artículo 3 de la Nueva Ley 19.948 de Matrimonio Civil dispone que «las materias de familia reguladas por esta ley deberán ser resueltas cuidando proteger siempre el interés superior de los hijos y del cónyuge más débil».

De todo lo expresado, se obtiene una primera conclusión básica, en cuanto en la audiencia de juicio en que se resuelva si se confirma la afectación provisoria de un bien como familiar, el juez, de acuerdo con las normas del párrafo referido, así como de las demás del derecho de familia, deberá ser muy cuidadoso para analizar en detalle y ponderar todos los antecedentes que puedan justificar una resolución en ese sentido.

En primer lugar, el juez deberá concluir que el inmueble, al que se pide afectar como «bien familiar», constituye efectivamente la residencia principal de la familia, es decir, de ambos cónyuges y todos los hijos, si los hubiere. Este requisito, que es esencial, empieza a debilitarse en el momento en que los cónyuges acuerdan el cese de la convivencia, donde se inicia el proceso de disolución de esa familia. En esa circunstancia el juez deberá atender, principalmente, al «interés de los hijos».

Es muy interesante la disposición legal del artículo 147 del Código Civil, que obliga al juez a tener especialmente en cuenta, además, «las fuerzas patrimoniales de los cónyuges», ya que cuando se inicia este proceso de término de la familia con el cese de la convivencia pueden ser muy distintas la situación de trabajo y de patrimonio de marido y mujer que les permitan cumplir con sus obligaciones de sustento con los hijos.

En esta línea de razonamiento, en lo relativo a los alimentos que se deben por ley a algunas personas se permite que, en caso de imposibilidad de los padres, también el patrimonio de los abuelos pueda ser considerado para efectos de fijar pensión de alimentos a los hijos menores.

El efecto de la declaración judicial de afectar un bien como familiar está contemplado en el artículo 142 del Código Civil, que dispone:

No se podrán enajenar o gravar voluntariamente, ni prometer gravar o enajenar, los bienes familiares, sino con la autorización del cónyuge no propietario. La misma limitación regirá para la celebración de contratos de arrendamiento, comodato o cualesquiera otros que concedan derechos personales de uso o de goce sobre algún bien familiar.

La ley contempla la desafectación de un bien declarado «familiar», en primer lugar, de común acuerdo entre los cónyuges, según dispone el artículo 145 del Código Civil.

La misma norma permite que el cónyuge propietario pueda pedir al juez la desafectación de un bien familiar fundado en que no está, actualmente, destinado a los fines que indica el artículo 141.

Efectivamente, puede suceder que con posterioridad a la declaración de un bien como familiar se produzcan diversas circunstancias que modifiquen sustancialmente la estructura de aquella familia, o bien afecten las condiciones patrimoniales o de trabajo de uno o de ambos cónyuges, así como que dicho inmueble no sirva de residencia principal a esa familia o que esta simplemente se haya extinguido.

En estos casos, el cónyuge propietario tendrá derecho a solicitar la desafectación del 
bien, «lo que deberá probar», debiendo procederse por el juez de la misma manera ya mencionada en que se actuó para la declaración de aquel bien como familiar, según se ha comentado en este mismo párrafo.

Agrega la norma que igual regla se aplicará en tres situaciones: declaración de nulidad del matrimonio, muerte de uno de los cónyuges o divorcio. Estas tres causales indican que, efectivamente, esa familia ya dejó de existir, por lo que nace para el cónyuge propietario o «cualquiera de sus causahabientes» el derecho a pedir la desafectación del bien.

\section{Efectos que produce la declaración de un bien como familiar}

La afectación de un inmueble como «bien familiar» produce una muy importante limitación al dominio por cuanto para efectuar actos de disposición sobre el mismo, como enajenar o gravar esos bienes, el propietario requiere la autorización de su cónyuge o, en subsidio, del juez.

Si hubiere necesidad de gravar o enajenar el bien familiar en caso de negativa injustificada del cónyuge no propietario para autorizar la disposición del bien, esta autorización la puede conceder el juez.

Para una precisa comprensión del efecto jurídico que deriva de la decisión judicial que declara «familiar» a un bien inmueble y los muebles que la guarnecen, en cuanto limita severamente las facultades del dueño, debe considerarse la garantía constitucional del derecho de propiedad. Esta garantía se encuentra establecida en el artículo 19 numeral 24. ${ }^{\circ}$ inciso segundo de la Constitución Política, que dispone: «Solo la ley puede establecer el modo de adquirir la propiedad, de usar, gozar y disponer de ella y las limitaciones que deriven de su función social».

La facultad esencial del dominio sobre un bien es la disposición del mismo, pudiendo el propietario gravarlo o enajenarlo sin limitación de ninguna especie. El derecho a la venta de un bien propio, es decir, su enajenación, es una garantía de orden constitucional que no puede ser limitada, sino en virtud de una ley.

En razón de lo anterior, en el inciso tercero del mismo artículo 19 numeral $24{ }^{\circ}$ de la Constitución Política se agrega lo siguiente:

Nadie puede, en caso alguno, ser privado de su propiedad, del bien sobre que recae o de alguno de los atributos o facultades esenciales del dominio, sino en virtud de una ley general o especial que autorice la expropiación por causa de utilidad pública o de interés nacional, calificada por el legislador.

En un primer análisis, pareciera existir una especie de contradicción entre la norma del artículo 19 numeral 24. ${ }^{\circ}$ de la Constitución y la del artículo 142 del Código Civil, en cuanto en la primera de ellas se garantiza el ejercicio del derecho de propiedad, de sus atributos y facultades esenciales, y en el otro se establece una muy severa limitación al dominio con respecto a aquellos que han sido declarados bienes familiares.

Para resolver la cuestión, primeramente se deberá analizar la estructura del ordena- 
miento jurídico vigente en Chile, el que nos lleva al concepto de «primacía constitucional establecida en la Carta Fundamental».

Por otro lado, en lo relativo a la aplicación del derecho de familia, deberán considerarse especialmente aquellas normas que reglamentan las relaciones patrimoniales entre los cónyuges y de los padres con sus hijos, así como las de interpretación de la ley, contenidas en los artículos 19 al 24 del Código Civil.

\section{Normativa constitucional aplicable}

El punto de partida de este análisis se encuentra en las bases del sistema jurídico y económico de la República de Chile establecido en la Constitución Política, el que está organizado a partir del principio fundamental de la libertad de las personas consagrado en el inciso primero de su artículo 1, en cuanto «las personas nacen libres e iguales en dignidad y derechos». A continuación, y en forma inmediata, para que no quepa duda alguna con respecto a la importancia de la familia y de la vinculación que ella tiene con la dignidad y derecho de las personas, la Carta Fundamental agrega que: «la familia es el núcleo fundamental de la sociedad». En el inciso cuarto del mismo artículo se consagra el llamado "principio de la servicialidad», en que el Estado, a través de sus órganos, es decir, tanto el Poder Ejecutivo como el Congreso y también el Poder Judicial, deben permitir a los ciudadanos «su mayor realización espiritual y material posible con pleno respeto a los derechos y garantías que esta Constitución establece» (artículo $1^{\circ}$ ).

Lo anterior significa que cada uno de los Poderes del Estado en sus actuaciones propias debe, necesariamente, procurar que este principio de la servicialidad se aplique en toda su plenitud a los ciudadanos que aquella actuación pueda afectar.

Sobre esta materia, el profesor de Derecho Administrativo de la Facultad de Derecho de la Universidad de Chile, Rolando Pantoja Bauzá, ha señalado que «el artículo 1 de la Constitución es un precepto de obligado acatamiento para todos los órganos del Estado», a lo que agrega que «esta perspectiva constitucional ha llevado a los tribunales superiores de justicia a considerar al artículo 1 como un precepto orientador de la interpretación constitucional» (Pantoja Bauzá, 2009: 78).

En este sentido, el profesor Pantoja cita un fallo de la Corte de Apelaciones de Santiago que concluyó que «el derecho a vivir en un medioambiente libre de contaminación es un derecho absoluto, basado en la dignidad del ser humano, consagrado en el artículo 1 de la Carta Constitucional» (Pantoja Bauzá, 2009: 78).

Confirmando dicha doctrina, el profesor Pantoja cita un fallo del Tribunal Constitucional que señala que:

El artículo 1 de la Carta Fundamental constituye uno de los preceptos fundamentales en que se basa la institucionalidad, ya que por su profundo y rico contenido doctrinario refleja la filosofía que inspira nuestra Constitución y orienta al intérprete en su misión de declarar y explicar el verdadero sentido y alcance del resto de la preceptiva constitucional (Pantoja Bauzá, 2010: 77). 
En suma, en virtud de la forma en que se inicia el primer capítulo de la Constitución estableciendo las bases de la institucionalidad, se ha reconocido que la Carta Fundamental es esencialmente libertaria y orientada a proteger la dignidad y derechos de todas las personas, consagrando a la familia como núcleo fundamental, la que nace como consecuencia de una decisión libre de quienes le dan origen, los cónyuges.

Es por ello que en el artículo 19 de la Constitución se establecen derechos esenciales para todas las personas, como el derecho a la vida, a la igualdad ante la ley, a la defensa jurídica, a la libertad personal, a la libertad de enseñanza, a la libertad de emitir opiniones sin censura previa, el derecho a reunión y el derecho de asociarse sin permiso previo, entre otros.

En lo que se refiere a la libertad personal relacionada con el emprendimiento, el trabajo y el desarrollo profesional, se consagran por la Constitución Política, entre otras, las siguientes garantías constitucionales: la libertad de trabajo y protección, la no discriminación arbitraria en el trato que deben dar el Estado y sus organismos en materia económica, la libertad para adquirir el dominio de toda clase de bienes, la libertad de crear y difundir las artes, y el derecho de autor.

Particular importancia adquiere la garantía constitucional relativa al derecho a desarrollar cualquiera actividad económica, que no sea contraria al orden público o a la seguridad nacional, respetando las normas legales que la regulen contempladas en el numeral 21 del artículo 19 de la Constitución Política.

En cuanto a la interpretación de toda la normativa constitucional, cabe tener en cuenta lo señalado en la sentencia del Tribunal Constitucional, rol 325, del 26 de junio de 2001, que citando doctrina de tratadistas expresa que:

En la interpretación constitucional debe siempre prevalecer el contenido teleológico de la Constitución, que, si es instrumento de gobierno, también, y principalmente es restricción de poderes, en amparo de la libertad individual. La finalidad suprema y última de la norma constitucional es la protección y la garantía de la libertad y la dignidad del hombre (considerando tercero). ${ }^{1}$

Es importante destacar el refuerzo que establece la Constitución contemplado en el numeral $26 .^{\circ}$ del artículo 19 , que garantiza:

La seguridad de que los preceptos legales que por mandato de la Constitución regulen o complementen las garantías que esta establece o que las limiten en los casos en que ella lo autoriza no podrán afectar los derechos en su esencia, ni imponer condiciones, tributos o requisitos que impidan su libre ejercicio [el énfasis es nuestro].

1. Citado en Andreucci Aguilera (2008: 17). 


\section{Libertad de emprendimiento y patrimonio de las personas}

La protección constitucional a la libertad de emprendimiento de las personas ha sido comentada por diversos tratadistas, que es conveniente destacar.

El profesor de la Universidad de Chile Enrique Navarro Beltrán, autor de numerosas publicaciones y quien fuera Ministro del Tribunal Constitucional, ha efectuado diversas publicaciones académicas acerca de la garantía contemplada en el artículo 19, numeral 21, sobre libertad para emprender cualquier actividad económica. Entre ellas, destaca el libro La Constitución Económica chilena ante los Tribunales de Justicia, publicado en dos tomos en 2016 y 2018.

A este respecto, en el primer tomo se encuentra la cita de la siguiente sentencia de la Corte de Apelaciones de Santiago del 25 de mayo de 1996, señalando que el artículo 19, numeral 21. ${ }^{\circ}$ :

Comprende la libre iniciativa y la prosecución indefinida de cualquier actividad económica, sea productiva, comercial, de intercambio o de servicio, habiendo sido introducida por el constituyente de 1980, con especial énfasis y estudio, según consta de la historia fidedigna del precepto (Navarro Beltrán, 2016: 46).

En otro fallo del mismo tribunal, del 19 de marzo de 1992, citado por el mismo profesor Navarro, se agrega que ello puede realizarse «libremente, personalmente o en sociedad, organizada en empresas, en cooperativas o en cualquier otra forma de asociación lícita» (Navarro Beltrán, 2016: 47).

Mas adelante, en la misma publicación se cita una sentencia de la Corte de Talca del 18 de febrero de 2008 , en que se expresa que la libertad económica consiste en:

La facultad natural de los hombres de ser agentes decisorios y responsables en materia de producción y distribución de la riqueza. Se pretende que el hombre, como ser inteligente y responsable de sus actos, pueda participar y tomar decisiones con la menor cantidad de trabas y obstáculos posibles en las distintas etapas del ciclo económico general (Navarro Beltrán, 2016: 49).

En las conclusiones del primer capítulo del citado libro, el profesor Navarro señala que:

Dicho derecho es de contenido amplio e importa la libertad que se garantiza a todas las personas, sean naturales o jurídicas, para satisfacer sus necesidades -múltiples e ilimitadas - mediante la utilización de bienes escasos y limitados, no siendo indispensable, por tanto, el carácter lucrativo de las aludidas actividades económicas (Navarro Beltrán, 2016: 64).

En el mismo sentido, la profesora Luz Bulnes Aldunate señala que:

El constituyente del 80 junto con consagrar la libertad de trabajo y su protección ha establecido expresamente otro derecho individual que viene a ser su complemento, como también expresión de la libertad personal, y tiene por fundamento dar un res- 
guardo a la libertad económica protegiendo la iniciativa privada (Bulnes Aldunate, 1985: 149).

El profesor Teodoro Ribera Neumann coincide con lo anterior al señalar que:

La libertad económica constituye un derecho propio del ser humano, siendo en forma importante una condición necesaria, aunque no suficiente para la democracia. La libertad económica permite ofrecer a otros que eligen, la creatividad humana en forma de bienes y servicios, lo que conlleva reconocer y resguardar el derecho a las personas de buscar su propia realización personal y no imponerles aquella establecida por el Estado. La libertad económica facilita, además, que los éxitos individuales sean debidamente recompensados y las fallas sancionadas. Ello le otorga a la libertad económica relevancia desde el punto de vista de la producción y distribución de los bienes, pero también un fundamento ético y social: Para que existan oportunidades de ser más, debe igualmente garantizarse la libertad de asumir el riesgo de la ganancia o pérdida (Ribera Neumann, 2001: 404; el énfasis es nuestro).

De esta manera, los ciudadanos, buscando su propia realización personal, ejercen libremente su vocación y emprenden tareas profesionales, de trabajo y empresariales, por las que procuran obtener algún ingreso para satisfacer sus necesidades y las de su familia. Con sus ingresos, las personas adquieren bienes - muebles e inmuebles - y forman su patrimonio, sobre el que la Constitución les garantiza el derecho de dominio.

En una perspectiva sociológica y económica, el profesor Carlos Peña ha expresado en una publicación reciente que «el intercambio posee un lugar muy relevante en las sociedades humanas [...] y que ha extendido su presencia, bajo la forma de mercado, hacia casi todos los intersticios de la vida social en el capitalismo moderno» (Peña González, 2018: 187). Además, señala que:

Así, si puede discutirse que el intercambio tiene límites morales, lo que parece indudable es que el dinero y el mercado también ha hecho posible la existencia de muchos bienes de carácter indudablemente moral, que las sociedades humanas tienen hoy en alta estima (Peña González, 2018: 188).

A continuación, se pregunta el profesor Peña cuáles son esos bienes. La respuesta la proporciona de inmediato: «El primero de todos es el de la libertad» (Peña González, 2018: 188).

\section{Antecedentes de la historia de esta norma}

Es interesante, a este respecto, considerar el informe de la Comisión de Constitución, Legislación, Justicia y Reglamento del Senado del 5 de octubre de 1993 que está publicado en la Revista Chilena del Derecho.

El senador Hernán Vodanovic señaló que esta norma podría generar problemas por el hecho de que el inciso segundo del numeral $24 .^{\circ}$ del artículo 19 de la Constitución Política establece como condiciones para que la ley pueda imponer limitaciones 
al dominio en virtud de la función social que ellas, en lo pertinente, obedezcan a los «intereses generales de la Nación» o a la «utilidad pública», es necesario determinar si el proyecto cumple alguno de estos requisitos y no configura una privación de atributos o facultades esenciales del dominio, en los términos del inciso tercero del mismo precepto (Senado de la República de Chile, 1994: 410)

El senador Sergio Fernández fue partidario de no crear la institución de bienes familiares porque, en su opinión, su utilidad es muy dudosa y revestiría aspectos de inconstitucionalidad (Senado de la República de Chile, 1994: 411). Asimismo, agrega que:

La Constitución establece en su artículo 19, numeral 26, que las garantías constitucionales no pueden ser afectadas en su esencia y, obviamente, la esencia del derecho de propiedad está constituida por las facultades de usar, gozar y disponer del bien sobre el cual se tiene dominio, y, muy particularmente, con la facultad de disponer que es la que distingue a este derecho real de todos los demás (Senado de la República de Chile, 1994: 412).

El Acta contiene consultas al profesor Carlos Peña, quien concurrió a dichas sesiones en calidad de asesor del Servicio Nacional de la Mujer:

Manifestó que el proyecto contiene medidas adecuadas para precaver los abusos que se pudieran producir, la sanción de indemnización de perjuicios para el cónyuge que hiciere fraudulentamente la declaración y la posibilidad de reclamar ante la justicia, en caso de que el cónyuge propietario estime que no corresponde la declaración de bien familiar (Senado de la República de Chile, 1994: 416).

Se concluye que al estudiar la norma durante el proceso de discusión legislativa, diversos senadores, de distintas posiciones políticas, expresaron su preocupación por el impacto constitucional que podría causar el instituto de los bienes familiares.

\section{Limitaciones legales al dominio}

En lo que se refiere a las posibles limitaciones al dominio que podrían establecerse por la ley, el profesor Julio Alvear Téllez de la Universidad del Desarrollo, de la misma manera que los otros tratadistas y profesores citados más atrás en este informe, concluye que:

La libertad económica fue concebida por el constituyente como una derivación del principio antropológico de la libertad del hombre y de su primacía sobre el Estado. Tal libertad, se trazó originariamente como una proyección de la autonomía personal, en el ámbito del desarrollo empresarial y productivo (Alvear Téllez, 2015: 321).

En dicho trabajo el profesor Alvear Téllez concluye que «en todos los aspectos donde la libertad económica y el bien común podrían disociarse, se requiere un esfuerzo de composición armónica» (Alvear Téllez, 2015: 362).

En esta misma línea de razonamiento, el profesor de Derecho Constitucional de la 
Pontificia Universidad Católica de Valparaíso, Eduardo Aldunate Lizana, analiza un tema de gran trascendencia: la distinción entre los conceptos de limitación del dominio y de expropiación. A este respecto, cita un criterio tomado del derecho español en el que para diferenciar un acto de limitación al dominio de otro acto que signifique expropiación, debe atenderse al «enriquecimiento», en el que se concluye que si del análisis particular de un caso concreto se está en presencia de un enriquecimiento para alguna parte, sea privada o pública, ello constituiría una «expropiación» y no una limitación al dominio, admitida por la Constitución y por la ley (Aldunate Lizana, 2006: 285).

\section{Libertad de emprendimiento y responsabilidad patrimonial}

Ahora bien, esta garantía de la libertad que se otorga por la Carta Fundamental a todas las personas genera, correlativamente, la obligación de responsabilidad, ya que los ciudadanos deben cumplir con todas las obligaciones que les impone la ley o las que voluntariamente han aceptado.

En este sentido, la libertad para generar obligaciones de carácter patrimonial supone, necesariamente, también la responsabilidad personal por aquellas obligaciones.

Por lo anterior, existe el llamado «derecho general de prenda de los acreedores», contemplado en el artículo 2465 del Código Civil, que dispone que toda obligación personal da a los acreedores el derecho de perseguir su ejecución sobre todos los bienes de los deudores. Se ha definido este derecho como:

La afectación, por el solo ministerio de la ley, de la totalidad de los bienes embargables del deudor, al momento de contraer la obligación, a fin de asegurar el cumplimiento de la misma, facultando al acreedor para exigir su realización y hacerse pago con las modalidades y preferencias consagradas en la ley (Rodríguez Grez, 2003: 289).

De esta manera, las personas, en el desarrollo de sus emprendimientos, pueden enajenar parte de su patrimonio para cumplir con sus obligaciones. El derecho a vender uno o más bienes que les pertenecen es fundamental para que los ciudadanos no defrauden a sus acreedores y mantengan intacto tanto su nombre como su prestigio.

La ley reconoce expresamente este concepto en materia de «bienes familiares» en el inciso final del artículo 147 del Código Civil, que dispone que «la constitución de los mencionados derechos sobre bienes familiares no perjudicará a los acreedores que el cónyuge propietario tenía a la fecha de su constitución» (inciso final).

Si bien es cierto que la ley establece que los acreedores anteriores a la fecha de constitución de los bienes familiares no verán afectados sus derechos, cabe pensar que de todas maneras al congelar la capacidad del cónyuge propietario para disponer de su propio bien se limita también este derecho de prenda general con respecto a obligaciones futuras. En consecuencia, se limita también la capacidad del cónyuge propietario para generar recursos financieros con cargo a estos bienes.

Por todo lo expresado, bien se puede concluir que la afectación de un bien inmueble puede, en ciertos casos, significar una limitación muy grave al derecho de dominio del 
cónyuge propietario, que puede llegar hasta la paralización total de su libertad de emprendimiento impidiendo que este pueda enajenarlo o gravarlo para obtener recursos necesarios para ese emprendimiento.

\section{Derecho al debido proceso}

De todo lo expresado en este trabajo se concluye que la responsabilidad del tribunal de familia que debe resolver sobre esta materia es muy alta. Reiterando lo expresado en el párrafo uno: en la audiencia de juicio, en que se resolverá derechamente tal petición, la parte que solicite la afectación deberá acompañar todos los antecedentes que la justifiquen, los que de acuerdo con la normativa aplicable a estos tribunales el juez deberá estudiar cuidadosamente.

Lo anterior nos lleva a la garantía constitucional del debido proceso, establecida en el numeral $3 .^{\circ}$ del artículo 19 de la Constitución Política, que establece que:

Toda sentencia de un órgano que ejerza jurisdicción debe fundarse en un proceso previo legalmente tramitado. Corresponderá al legislador establecer siempre las garantías de un procedimiento y una investigación, racionales y justos (inciso sexto).

Sobre esta materia, el profesor Enrique Navarro menciona un fallo del Tribunal Constitucional expresando que «la motivación de la sentencia es connatural a la jurisdicción y fundamento indispensable para su ejercicio, y no un acto discrecional de su voluntad autoritaria» (Navarro Beltrán, 2016: 255). ${ }^{2}$

En la misma publicación se cita al jurista Eduardo Couture, quien en su obra Fundamentos de Derecho Procesal Civil señala que la obligación de motivar la sentencia se le impone al juez:

Como una manera de fiscalizar su actividad intelectual frente al caso, a los efectos de poder comprobar que su decisión es un acto reflexivo, emanado de un estudio de las circunstancias particulares, y no un acto discrecional de su voluntad autoritaria (Navarro Beltrán, 2016: 256; el énfasis es nuestro).

Entrando al análisis de las disposiciones legales del derecho de familia, para tratar de resolver esta aparente contradicción entre la norma de carácter constitucional y aquella de derecho civil que establece los bienes familiares, el tribunal deberá analizar aquellas pertinentes sobre esta materia.

En primer lugar, deberán tenerse presentes las reglas de interpretación de la ley contenidas en los artículos 19 a 24 del Código Civil, que contemplan una especie de secuencia entre los elementos gramatical, histórico y lógico de las disposiciones legales.

Además de esas reglas de interpretación, será necesario considerar el elemento sistemático establecido en el artículo 22 del mismo cuerpo legal, sobre el cual la Corte Suprema ha resuelto que:

2. Se remite a (Sentencia del Tribunal Constitucional, rol 1373-09, 2010: considerando decimoquinto) 
Para interpretar una norma jurídica no puede procederse a considerar solo un fragmento de ella, aislándolo del resto de que forma parte integrante y mirarlo como una regla separada e independiente, pues así se llega a cambiar su significado. El conocimiento del verdadero sentido de una norma, su interpretación y aplicación cabal, exigen indispensablemente examinarla en su total contenido y amplitud (Andreucci Aguilera, 2008: 31).

Adicionalmente, deberá tener presente lo establecido en el artículo 24, que dispone que «se interpretarán los pasajes oscuros o contradictorios del modo que más conforme parezca al espíritu general de la legislación y a la equidad natural» (Código Civil de la República de Chile, 1857: artículo 22, inciso $2^{\circ}$ ).

En lo específicamente referido a la petición de uno de los cónyuges para que se declare «bien familiar» un inmueble, el artículo 141 del Código Civil requiere, como se dice al principio de este informe, que se presenten «los antecedentes que la justifiquen». Ello también es necesario en lo relativo a la solicitud de desafectación de un bien, contemplada en el artículo 145 del mismo Código.

Cabe recordar que la ley, en estas materias, exige que el juez efectúe un muy cuidadoso estudio y análisis de dos condiciones que son principales para resolver: «el interés de los hijos y las fuerzas patrimoniales de los cónyuges».

Similar criterio contempla el artículo $3^{\circ}$ de la Ley 19.947, que hace referencia también al «interés de los hijos» y a otro concepto muy relacionado con las fuerzas patrimoniales de los cónyuges, cual es «la situación del cónyuge más débil». Esta línea de pensamiento se encuentra presente en todas las disposiciones legales relativas a la protección de la familia común.

Es así que el artículo 134 del Código Civil dispone que el marido y la mujer deben proveer a las necesidades de la familia común «atendiendo a sus facultades económicas $\mathrm{y}$ al régimen de bienes que entre ellos medien».

El artículo 222 del mismo cuerpo legal reitera que la preocupación fundamental de los padres es «el interés superior del hijo», lo que ratifica el artículo 224 en cuanto dispone que «toca de consuno a los padres, el cuidado personal de sus hijos».

Particular importancia tiene la norma del artículo 230 del Código Civil, que en lo relativo a los gastos de educación, crianza y establecimiento de los hijos dispone que «los padres contribuirán en proporción a sus respectivas facultades económicas».

A mayor abundamiento, el artículo 232 del mismo cuerpo legal dispone que en caso de insuficiencia de ambos padres, la obligación de alimentar al hijo que carece de bienes pasa a sus abuelos.

Resumiendo las reglas de interpretación señaladas, el juez deberá considerar estos criterios para establecer el espíritu general aplicable en nuestro sistema jurídico, tanto en lo referido a la garantía constitucional del dominio como a la necesaria protección a la familia, principalmente los hijos.

En este sentido, la norma del artículo 26 bis de la Ley 19.968 que crea los tribunales de familia es muy clara y terminante al precisar las tareas que corresponden al 
juez: «El juez que preside la audiencia ordenará la rendición de pruebas y moderará la discusión».

Incluso más, la facultad que el mismo artículo concede al tribunal para impedir que las alegaciones se desvíen hacia aspectos no pertinentes o inadmisibles significa, en verdad, que el juez tiene la obligación de centrar toda la discusión y debate en aquello que sea adecuado al caso y necesario.

En primer lugar, el tribunal, en aquella audiencia de juicio en que se debe resolver esta materia, deberá atender al «interés de los hijos». En este sentido, se deberán establecer sus necesidades principales de vivienda, educación, salud y otras, y resolver cómo, y de qué manera, cada uno de los cónyuges está contribuyendo a satisfacer estas necesidades. Este es un análisis principal, de gran contenido y profundidad que no puede ser pasado por alto, ni tampoco solo con menciones genéricas.

En cuanto a la determinación de las «fuerzas patrimoniales» de cada uno de los cónyuges, deberá precisarse con claridad la situación del inmueble cuya afectación se solicita, indicando antecedentes de la compra de dicho bien, su precio y la forma en que este constituye, efectivamente, la residencia de toda la familia. Se deberá indicar si existe deuda hipotecaria, la forma y manera en que los cónyuges concurren a su pago.

Adicionalmente, se deberá establecer si los cónyuges tienen otros bienes inmuebles, así como el uso y destino que se les da.

Por otro lado, complementando este análisis de carácter patrimonial, se deberá precisar si los cónyuges tienen participación en sociedades o empresas y el valor que se asigna a dicha participación, así como si perciben dividendos y utilidades.

\section{Comentarios sobre una sentencia}

La Corte Suprema, por sentencia de la Cuarta Sala del 4 de mayo de 2016 en causa rol 11514-2015, acogió un recurso de casación en el fondo y anuló una sentencia de segunda instancia dictada por la Corte de Apelaciones de Talca, que confirmaba fallo del Juzgado de Familia de Linares en que se rechazó la demanda por la que se pedía declaración de bien familiar del inmueble de uno de los cónyuges.

El fundamento principal para acoger el recurso de casación en el fondo se encuentra en el considerando octavo, que expresa lo siguiente:

Que esta Corte concluye que el inmueble de uno de los cónyuges sirve de residencia principal de la familia, pese a la separación de los cónyuges, cuando está ocupado por uno de ellos y los hijos comunes, aunque sea solo uno, lo que ocurre en la especie, sin que sea indispensable que haya sido el mismo que la familia ocupó durante el desarrollo de la vida común.

Del mismo modo, no puede vincularse el examen de este requisito legal con consideraciones sobre la posición patrimonial de los cónyuges o de los hijos, y con sus conductas o comportamientos en ese ámbito, pues ello significaría introducir elementos o factores que la ley no tomó en cuenta y que, por tanto, el juez no puede estimar a riesgo de rela- 
tivizar la aplicación del instituto. Todo ello sin perjuicio de que esas situaciones podrán ser motivo de otras ulteriores acciones, derechos o cuestionamientos de revisión por las vías correspondientes (Sentencia de la Corte Suprema de Justicia, rol 11514-2015, 2016, considerando octavo).

Se puede observar del considerando transcrito que la Corte Suprema sería de opinión que para resolver sobre la declaración de un bien familiar, debiera tenerse presente solo la interpretación literal del artículo 141, y que cualquier otra consideración, como lo expresa el fallo, sobre «la posición patrimonial de los cónyuges», no puede ser admitida, por cuanto ello significaría relativizar la aplicación de este instituto jurídico nuevo, como son los bienes familiares.

Llama la atención dicho criterio, ya que el mismo artículo en comento señala en forma expresa que estos bienes familiares «se regirán por las normas de este párrafo». Como se ha visto a lo largo de este trabajo, dicho párrafo menciona con claridad criterios relativos al «interés de los hijos» $\mathrm{y}$ «las fuerzas patrimoniales de los cónyuges», así como «el interés de la familia».

La sentencia fue acordada por mayoría de votos, pero existió uno disidente del abogado integrante Álvaro Quintanilla Pérez, quien en la parte esencial de su voto expresó lo siguiente:

Que el deber de protección de la familia, la ley lo impone a ambos cónyuges y a él subordina el patrimonio de ambos, y en una afectación que es igualitaria, y proporcionada a la situación de cada cual, según lo demuestran los artículos 134, 230, 1.740 numeral 5 y 1.753 del Código Civil. No parece conciliable con ello reconocer la calidad de bien familiar cuando se han producido situaciones extrañas, determinando un gravamen desigual con respecto al cónyuge propietario frente al otro, adjudicatario del único inmueble de la sociedad conyugal y que enajenó de modo voluntario precisamente al hijo que vive con ella y para luego ocupar el recién adquirido por su marido, junto al mismo hijo. La restricción que a la gestión dispositiva del dueño implica la condición de bien familiar constituye una excepción a la garantía del dominio y al derecho de prenda general de los acreedores y, como tal, debe aplicarse con sujeción al sentido de la norma que la autoriza como única vía para procurar la disposición de una vivienda, considerando la familia en sentido amplio, incluyendo la situación del cónyuge propietario (Sentencia de la Corte Suprema de Justicia, rol 11514-2015, 2016, voto disidente; el énfasis es nuestro).

Efectivamente, según se concluye en este trabajo, la doctrina correcta sobre esta materia es la que fluye del voto disidente del abogado Quintanilla Pérez.

\section{Conclusión}

En definitiva, el juez deberá ser muy cauteloso para evitar que el cónyuge propietario tenga, además, que asumir la mayor parte de los gastos de mantención de esa familia, haciéndose responsable del pago de los dividendos hipotecarios, gastos de enseñanza, costo de salud, pensión alimenticia y otros. 
En otras palabras, considerando los principios que se comentan más atrás con respecto al derecho español, el tribunal de familia deberá evitar que se esté produciendo una transferencia de riqueza del cónyuge propietario al que no lo es y que solicita la afectación del inmueble como bien familiar.

Sostener lo contrario significaría que la resolución judicial que decreta la calidad de bien familiar para un inmueble pasaría a tener el efecto de una especie de expropiación de carácter jurisdiccional, lo que no se aviene con la estructura de la normativa vigente en el país.

La declaración de bien familiar produce el efecto de «congelar» la facultad de disposición que sobre él tiene el cónyuge propietario, lo que afecta adicionalmente diversas otras garantías que le otorga el sistema jurídico.

Efectivamente, también debe considerarse que la mencionada expropiación podría traducirse, en ciertos casos, en una paralización total de la libertad de emprendimiento del cónyuge propietario dañando, de esta manera, sus garantías esenciales contempladas en el artículo 1 de la Constitución Política en relación con la libertad de trabajo y la libertad de emprendimiento.

Asimismo, la declaración de bien familiar puede afectar la capacidad de pago futura del cónyuge propietario no solo con respecto a sus propias obligaciones, sino que también puede impedir la venta del bien, incluso en caso de necesidad económica apremiante si en ese evento no obtuviere la autorización del cónyuge no propietario o del juez en subsidio.

En conclusión, la afectación como familiar de un bien inmueble y de los muebles que lo guarnecen debe considerarse en nuestro ordenamiento jurídico como una situación absolutamente excepcional y que solo podría concederse en aquellos casos y circunstancias donde sea necesario, después de cumplido el análisis que se menciona en los párrafos precedentes, debiendo el tribunal considerar antes que nada el interés de los hijos y la equivalencia en las fuerzas patrimoniales de las personas a los cuales afecte.

\section{Referencias}

Aldunate Lizana, Eduardo (2006). «Limitación y expropiación: Scilla y Caribdis de la dogmática constitucional de la propiedad». Revista Chilena de Derecho, 33 (2), 285-303. DOI: 10.4067/S0718-34372006000200005.

Alvear Téllez, Julio (2015). «Hacia una concepción comprehensiva de la libertad económica. Un paradigma a desarrollar». Estudios Constitucionales, 13 (1): 321-372. Disponible en https://bit.ly/3azisTl.

Andreucci Aguilera, Rodrigo (2008). «Los conceptos de la Corte Suprema, sobre interpretación de la ley a través de sus sentencias». NOMOS. Universidad de Viña del Mar, 1: 11-39. Disponible en https://bit.ly/2QGjpaV.

Bulnes Aldunate, Luz (1985). «El derecho a desarrollar cualquier actividad económica». Revista de Derecho Público, 37-38: 149-165. DOI: 10.5354/0719-5249.2016.43703. 
Navarro Beltrán, Enrique (2016). La Constitución económica chilena ante los Tribunales de Justicia. Tomo I. Santiago: Universidad Finis Terrae.

Pantoja BauzÁ, Rolando (2009). Derecho Administrativo. 150 años de doctrina. Santiago: Jurídica.

Peña González, Carlos (2018). Lo que el dinero sí puede comprar. Santiago: Penguin Random House.

Ribera Neumann, Teodoro (2001). «Reflexiones en torno a la libertad de empresa en la Constitución de 1980». En Enrique Navarro Beltrán (editor), 20 años de la Constitución Chilena 1981-2001 (pp. 403-418). Santiago: Lexis Nexis.

Rodríguez Grez, Pablo (2003). Responsabilidad Contractual: Santiago: Jurídica de Chile.

Senado de la República de Chile (1994) «Constitucionalidad del Régimen de los bienes familiares». Revista Chilena de Derecho, 21 (2): 409-416. Disponible en https://bit.ly/2QEayX7.

\section{Sobre el autor}

José Luis López Blanco es abogado y licenciado en Ciencias Jurídicas y Sociales por la Pontificia Universidad Católica de Chile. Además, es diplomado en Comercio Exterior del Banco Central de Chile y en Economía Internacional por la Universidad de Chile. Ha sido profesor de Derecho Constitucional Económico, Nuevas Formas de Intervención Administrativa y Derecho Comercial en la Facultad de Derecho de la Universidad de Chile, de Comercio Internacional en la Facultad de Derecho de la Pontificia Universidad Católica de Chile y de Derecho Económico en la Facultad de Derecho de la Universidad Gabriela Mistral, entre otras cátedras. 